\title{
Language and Covid-19
}

\section{Corpus linguistics and the social reality of the pandemic}

\author{
Michaela Mahlberg and Gavin Brookes \\ University of Birmingham | Lancaster University
}

Covid-19 has turned the world on its head. The pandemic triggered a global state of medical emergency. But it is more than that. People the world over have been required to make sense of life in new ways. Language is one of the most fundamental tools we have to make sense of our social reality, including its foundational role in constructing and communicating our understandings and experiences of all matters relating to health and illness. As Fox (1993:6) puts it (see also Brookes \& Hunt, 2021):

illness cannot be just illness, for the simple reason that human culture is constituted in language $[\ldots]$ and that health and illness, being things which fundamentally concern humans, and hence need to be 'explained', enter into language and are constituted in language, regardless of whether or not they have some independent reality in nature.

As such, language has played a key role in this process of making sense of life in the context of Covid-19, and the language used to such ends can provide evidence of social experiences of the pandemic. Over the course of the pandemic, we have frequently witnessed "the science" being referred to as a way of explaining and legitimising political decisions and other measures designed to influence public behaviour. What the studies in this Special Issue focus on are the attitudes and beliefs that play a part in the lived experience of people during the pandemic, and how these are constructed and mediated through language use.

The broad objective of this Special Issue is to contribute to the study of language constituting different discourses around Covid-19- discourses which take place across different interactional and cultural contexts, and which are employed with different purposes in mind. Talking about Covid-19 involves dealing with the unknown, as Müller, Bartsch and Zinn's study shows. They approach uncertainty as a linguistically mediated social experience and identify trends in media discourses in Germany and the UK. Attitudes and opinions are present in 
all discourses on Covid-19, in the media as well as in academia. This is demonstrated by the article by Dong, Buckingham and Wu. Their study further stresses the link between linguistic forms and the context of language use by correlating corpus findings with information on Covid cases reporting. The relationship between language and context is crucial for the study by Hyland and Jiang, too. They draw attention to the competitiveness that characterises the language used to present research on Covid-19 amidst the increased volume and speed of scientific publishing triggered by the pandemic. As well as varying according to textual genres and interactional contexts, the ways we perceive and discursively construct Covid-19 are also contingent upon the particular languages we use and the cultures in which we are situated. This is demonstrated aptly by Curry and PérezParedes's comparison of stance nouns in Covid-19-related blog posts published in The Conversation in Spain and the United Kingdom. Through their use of comparable corpora, the authors also shed light on blogs as an emerging genre in the (public) construction of health-related knowledge. Blogs play a role in public communication by extending the reach of academic findings, which is particularly important in the context of a pandemic, but also increasingly vital for the impact of research more widely. Finally, just as different types of attitudes and beliefs can be expressed through language, so can the experience of emotions. McGlashan approaches the topic of grief and the way in which Covid-19-related bereavement has been experienced in the digital space, as his article examines networked discourses of bereavement in online memorials.

To complement the specific case studies presented in this Special Issue, the short paper by Davies introduces the Coronavirus Corpus, a resource to support the study of language in pandemic discourses. This methodological paper connects to a contribution in issue 25(3), where cOWIDplus Analysis and cOWIDplus Viewer are presented for the interrogation of a German-language newsfeeds corpus (Wolfer et al., 2020).

When we circulated the call for papers for this Special Issue in July 2020, we received over 100 proposals. This, we feel, is testament to the applied nature of corpus linguistics, as well as to the innovativeness of our research community to respond rapidly and creatively to the most urgent global challenges of our time. Taken together, the articles in this Special Issue present a snapshot of the many ways in which corpus linguistics can contribute to our understanding of how language is used to make sense of the world. We hope that the insights provided herein will help to further illuminate lived experiences of Covid-19, as well as research across disciplines that aims to understand the pandemic in its social contexts. 


\section{References}

Brookes, G., \& Hunt, D. (2021). Discourse and Health Communication. In G. Brookes \& D. Hunt. (eds.), Analysing Health Communication: Discourse Approaches (pp. 1-17). Palgrave Macmillan. https://doi.org/10.1007/978-3-030-68184-5_1

Fox, N. (1993). Postmodernism, Sociology and Health. Open University Press.

Wolfer, S., Koplenig, A., Michaelis, F., \& Müller-Spitzer, C. (2020). Tracking and analyzing recent developments in German-language online press in the face of the coronavirus crisis: cOWIDplus Analysis and cOWIDplus Viewer. International Journal of Corpus Linguistics, 25(3), 347-359. https://doi.org/10.1075/ijcl.20078.wol

\section{Address for correspondence}

Gavin Brookes

Linguistics and English Language

Lancaster University

County South

Lancaster LA1 $4 \mathrm{YL}$

United Kingdom

G.Brookes@lancaster.ac.uk

\section{Co-author information}

Michaela Mahlberg

Department of English Language and

Linguistics

University of Birmingham

M.A.Mahlberg@bham.ac.uk 